\title{
EXPERIÊNCIAS DOCENTES DE FORMAÇÃO CONTINUADA SOBRE GÊNERO E SEXUALIDADE NO ENSINO FUNDAMENTAL
}

\author{
TEACHING EXPERIENCES OF CONTINUING EDUCATION ON GENDER AND SEXUALITY IN \\ ELEMENTARY SCHOOL
}

https://orcid.org/0000-0001-9455-6269 Aline Madalena Martins ${ }^{\mathrm{A}}$ (D) https://orcid.org/0000-0002-8243-1562 Tânia Mara Cruz ${ }^{\text {B }}$

${ }^{\text {A }}$ Secretaria de Estado da Educação (SED), Tubarão, SC, Brasil

${ }^{B}$ Universidade do Sul de Santa Catarina (Unisul), Tubarão, SC, Brasil

Recebido em: 27 abr. 2021 | Aceito em: 9 jul. 2021 Correspondência: Aline Madalena Martins (alinemartinstb@hotmail.com)

\begin{abstract}
Resumo
A presente pesquisa busca analisar de que modo uma determinada experiência de formação continuada de professores sobre relações de gênero e sexualidade pode contribuir para novas práticas docentes. Dentro de uma abordagem materialista histórica e dialética e a partir de um roteiro semiestruturado, foram entrevistados nove profissionais que participaram de uma formação continuada sobre a temática em uma escola de educação básica na cidade de Tubarão/SC no ano de 2014. Os resultados indicam a incorporação de práticas pedagógicas críticas em relação aos binarismos de gênero, mas com pouca repercussão em atividades relacionadas à sexualidade.
\end{abstract}

Palavras-chave: formação continuada de professores; ensino fundamental; práticas pedagógicas; relações de gênero; sexualidade.

\begin{abstract}
This research aims to analyze how a certain experience of continuing teacher education about gender and sexuality relations can contribute to new teaching practices. Within a historical and dialectical materialist approach and semi-structured script, nine professionals, who participated in a continuing training on the subject in a basic education school in the city of Tubarão/SC, in the year 2014. The results indicate the incorporation of critical pedagogical practices in relation to gender binarisms, with little repercussion in activities related to sexuality, or a change in the world view in some aspects, but without incorporating new pedagogical practices.
\end{abstract}

Keywords: continuing teacher training; elementary education; pedagogical practices; gender relations; sexuality. 


\section{Introdução}

O cenário da educação brasileira está marcado por documentos que dispõem sobre a regulamentação das políticas educacionais, repercutindo assim nas escolas brasileiras. Tal fato pode ser notado no período que vai de 2010 a 2018, em que as questões de gênero e sexualidade vêm sendo retiradas de documentos já aprovados como o Plano Nacional da Educação (2014) e, na sequência, a Base Nacional Comum Curricular (2017). De um lado, temos grupos que ressaltam a luta por direitos, pela emancipação das mulheres e de grupos de Lésbicas, Gays, Bissexuais, Travestis, Transexuais e Transgêneros - LGBT. Do outro, grupos conservadores, cujos argumentos remetem-nos a períodos sombrios da história brasileira, compactuando com atitudes e políticas excludentes.

Desde os anos 1990, teorias a respeito de gênero e sexualidade vêm ganhando visibilidade, tanto no contexto acadêmico quanto em instituições e documentos internacionais que objetivam minimizar discriminações e buscam a igualdade de condições entre homens e mulheres. Com o fortalecimento de políticas públicas ligadas a esta temática e com a conquista de direitos da mulher e da comunidade LGBT em âmbito político, surgiram também os movimentos de oposição às discussões acerca de questões de gênero e sexualidade. Segundo Miguel (2016), as menções antigênero remontam à década de 1990, com conferências e documentos elaborados pela Igreja Católica, nos quais as lideranças da época mostraram-se preocupadas quanto a manutenção da composição familiar que julgavam como natural, fundamentados na identidade familiar heterossexual.

Avançando os anos 2000, observamos o surgimento do movimento Escola Sem Partido (ESP), fundado em 2004 pelo advogado e católico Miguel Nagib. O movimento foi caracterizado inicialmente pela oposição às discussões políticas na escola. Seus discursos iniciais sustentavam a ideia de que a escola é agente de doutrinação ideológica, que, por meio dos docentes, divulga ideias marxistas que influenciam negativamente desde as crianças até a juventude e incitam uma revolução socialista/comunista, contrariando os valores familiares.

Mendonça e Moura (2019) afirmam que para os defensores do ESP o professor age em sala de aula conforme interesses ideológicos e partidários, mediante um público passivo que acolhe informações como verdades absolutas sem qualquer tipo de reflexão. Estes entendem os estudantes como sujeitos desprovidos de senso crítico, incapazes de refletir, enquanto os professores são considerados manipuladores ideológicos. 
A partir da ideia de que os valores familiares devem ser intocáveis e isentos de interferência, o ESP abraça o discurso de defesa da "família natural" e passa a promover o pânico moral, atacando políticas de igualdade e de não discriminação (MIGUEL, 2016). O movimento ESP conta com a ideia da criminalização da docência, na qual a fusão dos defensores da imputação da "ideologia de gênero" e contrários ao que chamam de "doutrinação marxista" visa a intimidar profissionais de educação com notificações extrajudiciais contra quem ousar abordar esses assuntos na sala de aula (MOURA, 2016).

Já a entrada de pautas de oposição à questão de gênero, a chamada "ideologia de gênero", no cenário político brasileiro iniciou-se com deputados ligados às igrejas neopetencostais e aos setores mais conservador da Igreja Católica. Tal bancada de deputados caracteriza-se pelo fundamentalismo religioso, resistente aos debates que discutem políticas sobre o aborto, sexualidade e outros temas que julgam interferir nas questões morais e familiares.

Assim, as críticas sobre a inserção de gênero e sexualidade na escola vêm ganhando maiores proporções no embate entre os movimentos sociais e os defensores do movimento Escola sem Partido, que incluem em seu projeto a retirada de toda e qualquer discussão que esteja relacionada com a "ideologia de gênero", citada no parágrafo anterior. Cabe ressaltar que o termo "ideologia de gênero" é utilizado pelos seguidores do ESP, que se sustentam na ideia de que a teoria marxista é a referência teórica e a base para essa conspiração contra a família, que contraria a tradicional moral cristã em um conjunto de argumentos utilizados como forma de deslegitimar o debate sobre gênero e sexualidade na escola (MOURA, 2016).

Neste cenário de avanços e retrocessos em relação à educação brasileira, pesquisas apontam a importância da formação continuada de professores para promoção de uma educação de qualidade, uma vez que proporciona experiências pedagógicas docentes capazes de promover uma visão crítica que proporcione aos estudantes além do desempenho cognitivo, valores e práticas que transformem as relações de gênero na sociedade. Vale lembrar que o conceito de experiência que utilizamos ancora-se na concepção thompsoniana, que vê na dialética entre experiência vivida e experiência percebida a reflexão e superação do sujeito em processos de consciência críticos da sociedade capitalista e seus valores, de modo individual, mas, principalmente, coletivos (THOMPSON, 1981), que a nosso ver poderiam ser utilizados como referência para analisar a formação docente.

Mais do que políticas que promovam o acesso e a permanência de crianças e jovens à educação, é necessário que se faça da escola um espaço de modificação das relações de gênero. 
Boa parte das políticas educacionais norteiam formações docentes que parecem considerar que a escola é um espaço neutro e não questiona as experiências formativas que priorizam a formação para o currículo explícito e ignoram as relações cotidianas decorrentes do currículo oculto. Neste sentido, a escola continua a ser local de reprodução de sexismo, e a possibilidade de incorporar as questões de gênero na educação formal são frequentemente ignoradas, tornando-se um desafio superar o cenário de desigualdade de gênero (STROMQUIST, 2007). A formação docente poderia agir nas contradições presentes no universo escolar e propor fissuras e rupturas na ordem patriarcal e capitalista vigente.

\section{Procedimentos metodológicos}

A pesquisa que originou este artigo é resultante de dois momentos de ida a campo. Inicialmente houve um ano de formação docente, com encontros e práticas na escola, sendo que os encontros foram registrados por vídeo-gravações. Em 2018, houve o segundo momento durante o mestrado de uma das autoras, quando se deu o retorno junto às profissionais de educação que fizeram parte da formação, para a realização de entrevistas semiestruturadas sobre a memória de suas experiências com a formação vivida e suas práticas decorrentes, realizadas tanto na mesma escola como em outras no percurso de tempo dos 4 anos, desde a formação ocorrida em 2014.

O curso "Formação de Professores em Gênero, Raça e Diversidade Sexual" foi realizado em setenta e duas horas, distribuídas em encontros presenciais reflexivos e experiências docentes formativas na própria escola, com as participantes, que debateram temas teóricos, elaboraram e realizaram propostas de ação correspondentes aos temas discutidos em sala. Importante registrar nossos agradecimentos ao Fundo de Apoio à Manutenção e ao Desenvolvimento da Educação Superior (FUMDES), programa de concessão de Bolsas de Estudo, da Secretaria da Educação do Estado de Santa Catarina, que contribuiu parcialmente com a pesquisa.

Essa formação continuada foi oferecida pelo Programa de Pós-Graduação em Educação da Universidade do Sul de Santa Catarina a professores da Escola Municipal de Educação Básica (EMEB) Esmeralda Lino Silveira, uma escola de $1^{\circ}$ ao $5^{\circ}$ ano do município de Tubarão, em Santa Catarina. A formação resultou da parceria com a Secretaria de Educação Municipal, na época dirigida por um governo do Partido dos Trabalhadores (2013-2016), período em que a escola passa a ser de tempo integral. Ressalte-se que a escola situa-se em um bairro com 
crianças filhas de famílias pobres, trabalhadores/as com empregos instáveis, em um contexto de desemprego alto, violência e tráfico.

O curso contou com a presença de catorze participantes, sendo elas as professoras oficineiras, coordenadora pedagógica e diretora ${ }^{i}$ Todavia, nem todas conseguiram a frequência acima de 50\% em função de mudanças de escola, frequentes em uma cidade em que a grande maioria de professoras é admitida em contrato temporário (ACTs). Portanto, para este estudo selecionamos quem compareceu ao menos na metade dos encontros, o que nos levou a nove participantes.

Em 2018, cinco docentes ainda trabalhavam na EMEB Esmeralda Lino Silveira, sendo elas/es: Fabiana, diretora da escola; as professoras efetivas Silvana e Paula; a professora ACT Camila; e Fernando, professor oficineiro do Programa Mais Educação, único homem participante do curso. As demais professoras Lívia, Margarida e Marina, também contratadas temporariamente, trabalhavam em outras unidades escolares quando realizamos a pesquisa ${ }^{\mathrm{ii}}$. A professora oficineira Sueli, embora tendo se aposentado em 2018 foi entrevistada por ter participado do curso em 2014.

Aos registros audiovisuais da formação continuada produzidos pela professora que ministrou o curso em 2014, para os quais havia um Termo de Consentimento Livre e Esclarecido (TCLE), agregaram-se as entrevistas realizadas em 2018, com novo TCLE, cujos resultados compuseram parte da dissertação de mestrado de uma das autoras (MARTINS, 2019) $)^{\mathrm{iii}}$. As entrevistas ocorreram na EMEB Esmeralda Lino Silveira, ou seja, na escola em que estavam as participantes durante os momentos de hora-atividade. As entrevistas e as vídeogravações foram transcritas por nós.

Desde a ida a campo até o processo de análise nos baseamos na compreensão materialista histórico e dialética, que pressupõe uma relação dinâmica entre ser social e sujeito, e que os fenômenos sociais necessitam estar contextualizados em diferentes níveis de totalidade construídas em um contexto social, político, econômico (KONDER, 1992). Por isso, sobre nosso objeto de investigação efetuamos uma análise que busca as determinações, a partir de um olhar dialético acerca das conexões entre aspectos econômicos, sociais, políticos e culturais. Ao iluminar as contradições dentro da totalidade recortada para análise, evidenciamos as contradições internas e articulamos escola e sociedade.

Sobre a pesquisa materialista histórica e dialética, Wood (2007) nos fala sobre como as relações de produção implicam não só em uma lógica econômica, mas também em uma lógica de valores, normas e formas culturais específicas do mundo capitalista que auxiliam na 
manutenção do modo de produção vigente. Considerando os costumes, tradições e valores também como práticas que constituem a atividade produtiva, o materialismo histórico propõe como atividade teórica uma análise que permita evidenciar as condições e contradições existentes nas relações sociais e produtivas, decodificando os processos de continuidades e rupturas que revelam a operacionalidade do capital e que também produzem mudanças na consciência social de uma época.

\section{Articulando gênero e prática docente}

A escola é um espaço sociocultural que, ao dificultar a reflexão acerca das relações de gênero e sexualidade, às vezes, reproduz práticas normativas que expressam uma expectativa social dos comportamentos, em um posicionamento de subordinação ideologicamente legitimada (FORQUIN, 1993). Giroux (1997), ao fazer uma leitura do conceito de hegemonia de Gramsci, afirma que a dominação faz uso de um aparato cultural, disseminando práticas de controle social que guiam o comportamento cotidiano das pessoas. Em contrapartida, a escola pode ser, também, espaço de contestação aos modelos historicamente construídos, ao tratar o outro na perspectiva dos direitos humanos ou mais além, em uma educação emancipatória. Nesse sentido, Nóvoa (2013) atenta para a necessidade da incorporação de uma prática docente sustentada em atividades planejadas, dotadas de uma intencionalidade na qual o/a professor/a crítico/a pode oferecer momentos formativos em que estudantes passarão por experiências emancipadoras e reflexivas por meio de aprendizagens cognitivas e sociais, ultrapassando a ideia de transmissão de saberes constituídos na lógica conteudista.

$\mathrm{Na}$ concepção de uma ação pedagógica transformadora, a pedagogia pode vir acompanhada de objetivos previamente elaborados e de intervenção na realidade para que esta seja transformada. Esses objetivos exigem das/dos docentes uma reflexão sobre a realidade social, e conferem à ação pedagógica o sentido da práxis (PIMENTA; GHEDIN, 2002; VÁZQUEZ, 1997). A proposta aqui analisada de uma formação continuada docente que aliou debates teóricos a experimentações formativas sobre as relações de gênero com estudantes permite compreender limites e possibilidades de uma práxis que coloca em xeque padrões conservadores binários e heteronormativos de sexualidade e gênero.

Para compreender o conceito de gênero e suas implicações sociais, elemento chave de nossa análise, fundamentamo-nos em Connell (1990, p. 7), que afirma ser gênero uma construção histórica a respeito das ações desempenhadas por homens e mulheres, em um processo que gera uma identidade social "imposta sobre um corpo sexuado". A autora atenta 
ainda para o fato de a escola contribuir para a perpetuação de padrões normativos, que reproduzem a hegemonia masculina "através de estrutura de grupos de pares, controle do espaço escolar, padrões de encontros afetivossexuais, discursos homofóbicos e assédio" (CONNELL, 2013, p. 253). Apesar disto, a autora nos convida a pensar sobre a possibilidade de as escolas transformarem suas práticas, de forma a contestar tais padrões normativos, desconstruindo os binarismos de gênero e criticando a hegemonia masculina.

\section{Contextos da relação entre família e escola}

A relação entre família e escola é uma questão delicada quando tratamos das relações de gênero, e muitos debates em torno desta temática se deram durante o curso. Aqui analisamos os contornos destas relações e como as professoras passaram a lidar com as famílias em suas práticas após a realização do curso.

Esses contornos em relação às famílias, por vezes, foram anunciados de forma segura pelas professoras. Em outros momentos, suas falas revelaram como é delicada a relação entre a função social da escola e os valores de cada núcleo familiar, o que não as impediam de efetuar mudanças que considerassem viáveis acerca das relações de gênero no cotidiano da escola. Julgamos necessário, aqui, lembrar Louro (1994), quando afirma que as relações de gênero são acompanhadas de uma série de contradições que se expressam socialmente, e que o enfrentamento entre ambas pode apresentar entendimentos diferentes das famílias quanto às masculinidades e feminilidades. Suas narrativas podem vir acompanhadas de resistência e de acomodação frente às situações desencadeadas na educação ou, ainda, mostrar-se como possibilidade de mudança, de transformação, em que tais entendimentos podem sofrer modificações (LOURO, 1994).

Em nossa pesquisa, sistematizamos duas vertentes quanto à relação entre família e escola. Na primeira delas, presente tanto nas professoras efetivas ou temporárias da EMEB Esmeralda Lino Silveira, observamos o tom firme presente nos argumentos sobre o enfrentamento de situações relacionadas a gênero e sexualidade. Estas se mostram tranquilas quanto ao surgimento de problemas com as famílias. Em uma segunda vertente, no grupo de professoras que mudou de unidade escolar por conta dos contratos de admissão temporária, a tônica predominante foi a dificuldade em abordar a temática com os familiares. Vejamos:

Eu acho que é porque a gente trabalha mais nessa linha da inclusão, da diversidade... [...] A gente não pode fazer disso um bicho de sete cabeças... Eu acho que deve trabalhar sempre sim, o tempo todo, um trabalho que sempre vise à diversidade... Se acontece desse jeito, os pais não vão achar ruim [...] (Camila/ACT/ EMEB Esmeralda Lino Silveira). 
Lá a gente trabalhou o boi de mamão também. E tinha a Esmeralda, uma boneca [...]. Aí um menino, feliz da vida, ia carregar a Esmeralda. [...] A mãe, quando viu só esse menino com a boneca [na apresentação do Boi de Mamão], disse que não era para ele carregar a boneca. Aí nós tivemos que conversar com a mãe... explicar que não tinha nada demais ele carregar a boneca... que era uma apresentação muito bonita... E ele acabou ficando. (Sueli/Oficineira/Aposentada).

O medo da feminilização dos meninos é um dos pilares do binarismo de gênero que sustenta o sexismo no espaço familiar, e as professoras trouxeram relatos de diferentes atitudes formativas que tiveram com as crianças das suas turmas.

A crítica aos binarismos de gênero foi identificada nas entrevistas, mostrando que algumas professoras incorporaram um aprendizado em relação à liberdade nas formas de expressão das crianças, nos momentos de brincadeira e no próprio contexto da sala de aula.

[...] trabalhar com os alunos sem dizer que isso é para homem, isso é para mulher. Para mim o curso foi bem significativo. [...] independente se o menino brincar com a boneca... ele não ia deixar de ser menino... A menina que quisesse brincar de bola... [...] A criança pode brincar sem ter aquela vigilância, sem o professor dizer: 'Ah, larga isso porque...', sabe? (Margarida/ACT/EEB Fernando Gonçalves) ${ }^{\text {iv }}$.

Nas experiências relatadas pelas professoras, nos anos seguintes após a formação continuada de 2014, observa-se que elas passaram a criticar a organização sexista do espaço escolar e as atitudes que reforçam comportamentos heteronormativos. Essa mudança de visão de mundo foi perceptível quando a professora Margarida defendeu o fim da vigilância generificada sobre as brincadeiras infantis. Para Giroux (1997), estes momentos de reflexão docente transformam as condições em que trabalham, moldando os espaços, os tempos e as atividades que permeiam o cotidiano escolar, possibilitando às crianças uma nova interpretação da realidade. Margarida exemplifica:

Eu tenho um exemplo de um aluninho meu [...]. ele quer deixar o cabelinho crescer. [...] já teve gente falando que 'ah, não... é feio menino assim... '[...] Falar na sala [...] [orientar o aluno]. Quando surge, 'ah, é mulherzinha... 'tentar descontruir na sala essa ideia... e conversar com o aluno explicando isso (Margarida/ACT/ EEB Fernando Gonçalves).

A professora expressa uma preocupação com a linguagem sexista que explicita opressão, inferioridade e violência às mulheres e às diferentes orientações sexuais que no senso comum são vinculadas aos significados de gênero, e que caracterizam homofobia e discriminação sexual. A atenção constante e crítica é apontada por Franco (2016) como 
característica fundamental ao trabalho docente, no qual o professor, por meio das experiências vividas em sala de aula, está em constante reflexão e toma atitudes que correspondem ao que crê como essencial para a formação dos sujeitos que ali se encontram, em consonância com a sua formação pedagógica.

Surgiu momentos em que os meninos queriam brincar na casinha e tinha piadinha. Como a gente já tem esse olhar, o que que a gente fez? Disse que podia brincar. 'Mas quando tu cresceres, tu vais ter que fazer as coisas em casa também, então o que é que tem? E se tiver um bebê? Vai ter que ajudar a cuidar... 'Essas coisas vão mostrando o aprendizado nosso na formação... É essa sabedoria de lidar com essas situações [...] [sic]. (Fernando/Oficineiro/EMEB EMEB Esmeralda Lino Silveira).

[...] um dia aconteceu na sala. A menina disse: 'Ah, tia, o fulano samba muito, tia, ele rebola muito. 'Aí eu assim para o menino: 'Ah, deixa eu ver, como é que é? 'Aí outro aluno assim: 'Ai, tia... 'E eu: 'Oh, o que que tem demais? Eu também gosto de sambar... '(Paula/Efetiva/EMEB Esmeralda Lino Silveira).

A divisão sexual de trabalho foi um dos temas debatidos no curso, ocorrendo inclusive uma atividade de pesquisa junto às crianças que trouxeram de casa informações sobre como mães, pais e avós (e outros) realizavam o trabalho doméstico e fora de casa. Fernando expressa a crítica à divisão sexual do trabalho proposta pela criança, e Paula chama a atenção para a liberdade de expressão corporal e a possibilidade de um menino rebolar enquanto dança. Certamente, essa formas de interagir com as crianças implicam no que chamamos de críticas aos binarismos e contribuem para a reflexão das próprias crianças durante essas e outras experiências vividas por elas. A expressão tia, muito utilizada nos espaços da educação infantil da cidade pesquisada, foi problematizada na formação: nos registros audiovisuais há professoras que negam essa designação e outras que não se incomodam. Todavia, sua presença na fala de uma professora, durante a entrevista realizada4 anos após a formação, demonstra, ainda, a persistência da ideia tradicional de professora como segunda mãe, que marca o início da docência infantil no Brasil.

Mas, nem sempre as professoras conseguem a autonomia para o trabalho docente. Além disso, a resistência familiar aparece de muitas maneiras na sociedade, resultando em embates culturais, como os que temos visto atualmente, provocados pelos novos (velhos) grupos de direita que têm se (re)constituído. Ainda que essa resistência não seja recente, tendo sido citada em inúmeros estudos de gênero, com o crescimento do conservadorismo nas duas últimas décadas, particularmente na cidade de Tubarão, pais e mães tem se manifestado nas escolas expressando tal temor. Caberia verificar se a formação proporcionou segurança às professoras, e analisar quais as formas de dialogar com essa resistência eram criadas. 
Às vezes, a resistência torna-se exacerbada e professoras necessitam sustentar sua argumentação, até mesmo em recuos estratégicos, recorrendo aos conteúdos biológicos dos currículos de ciência como na situação a seguir:

O pai alegava que os professores iam ensinar sexo com as crianças na escola, iam mostrar o pênis para uma criança. Aí eu conversei com o pai. Expliquei assim: 'Ô, pai... essas questões de gênero é um trabalho como qualquer outro conceito. É um conteúdo transversal no currículo. E o jeito que o professor vai trabalhar aquilo vai depender da idade da criança, no sentido de respeitar a faixa etária, ensinar o respeito entre elas, o respeito do próprio corpinho. [...] Porque eles precisam saber que também é uma parte do corpo como qualquer outra, e eles têm curiosidade, então a gente tem que trabalhar o nome científico. Eu não vou trabalhar de forma vulgar, ou estar falando bileco, bilau, não! Eu vou trabalhar o nome científico, porque quanto mais claro for para a criança, mas ela vai ter o entendimento correto daquilo. Mas entre dizer o nome e falar do ato sexual tem uma grande diferença'. Aí eu tranquilizei o pai [sic] (Silvana/Efetiva/ EMEB Esmeralda Lino Silveira).

Como vimos nas video-gravações, a professora Silvana demonstrou uma compreensão ampla sobre a sexualidade, ao apresentar uma argumentação sustentada na visão biologicista, com o uso de nomes científicos e ênfase na faixa etária. Enfim, este foi um caminho seguro encontrado por ela para legitimar o trabalho da escola, mostrando para o pai a pertinência, enquanto ciência, do assunto na sala de aula.

A cidade de Tubarão/SC não ficou imune à crise política e ao acirramento do conservadorismo brasileiro quando emergiram os projetos da Escola sem Partido (ESP). Ao atualizar o Plano Municipal de Educação (PME), foi apresentado à Câmara Municipal de Vereadores de Tubarão uma emenda na qual incluía-se um artigo que proibia os termos gênero, orientação sexual ou quaisquer sinônimos que fizessem referência a direitos relacionados à equidade e à diversidade. A emenda foi alvo de discussões e de ações de inconstitucionalidade promovidas pela Câmara de Vereadores e Prefeitura na Procuradoria Geral da República. Na ocasião, a emenda não foi aprovada de imediato devido à luta de diversos setores sociais da cidade, inclusive da própria direção municipal, que naquele momento tinha à frente o Partido dos Trabalhadores (PT). Em 2015, porém, o PME foi aprovado com a inclusão do artigo $9^{\circ}$, que não permite a inclusão de tais temáticas no currículo escolar, sejam nas disciplinas obrigatórias ou de forma complementar. O curso, que ocorreu em 2014, é anterior à discussão do projeto do ESP em Tubarão, mas nas entrevistas esta temática foi incluída porque fazia parte do contexto histórico que movimentava a cidade e professoras/es das escolas que sofriam tais ameaças. Ao serem perguntadas se vinham acompanhando as discussões sobre a eliminação do termo gênero nos documentos oficiais sobre a educação no Brasil e o projeto de lei ESP, algumas docentes 
sentiram-se desconfortáveis, ou até mesmo amedrontadas em tratar da temática, o que repercutia nas suas relações com as famílias das crianças.

[...] tem muita informação distorcida. Por isso eu acho tão delicado. Porque dependendo de como a situação é trabalhada, o professor cai numa armadilha também, porque o professor vai ser atacado. É muito delicado isso para as famílias (Margarida/ACT/EEB Fernando Gonçalves).

Notamos que a dificuldade em tratar de gênero e sexualidade com a família tem se baseado na força que ganham os discursos conservadores, que apresentam os estudos e pesquisas na área de forma pejorativa e tendenciosa. Ao distorcerem a real definição do termo gênero para o novo termo ideologia de gênero, questionam e desqualificam o trabalho docente que problematiza as relações hierárquicas de gênero, a heteronormatividade, a homofobia, apesar das demandas que surgem dentro da escola (MATTOS et al., 2017). Tais proposições visam, justamente, desmoralizar e desmotivar o trabalho pedagógico na perspectiva de uma escola democrática, em defesa da pluralidade e da igualdade de direitos.

No tocante à sexualidade e relação com a família, ao ser perguntada sobre enfrentamento com os pais, Lívia explica:

[...] Nenhum pai veio reclamar, nem nada. Mas assim, é como eu disse, não é tudo que se fala em sala de aula como conteúdo mesmo. Pelo menos comigo as atividades eram bem leves para eles, nada que impactasse eles. Acho que é por isso que não teve reclamação disso. Mas não sei como seria, por exemplo, trabalhar mais em cima da sexualidade, essas coisas. Aí eu acho que provavelmente ia ter pai reclamando. [...] [Mas] Ensinar o respeito entre eles, entre todo mundo, nenhum pai vai ser contra isso [sic] (Lívia/ACT/EEB Emílio Peixoto).

Analisamos que Lívia relaciona o fato de não ter problemas com os pais ao que considera a sua forma leve de trabalhar, pautada em respostas genéricas a situações que surgem na sala de aula com as crianças, como no conceito de respeito, talvez mais voltado para uma ideia mais generalista acerca de Direitos Humanos. A professora parece evitar se arriscar com temáticas mais polêmicas.

Quanto às professoras em contratos temporários, ressalte-se que elas vivem uma realidade mais complexa, visto que regularmente trocam de escola, o que as deixam vulneráveis, numa condição de estrangeiras a cada escola que chegam. Além disso, no jogo entre diferentes valores, os pessoais, das professoras (as que ali já estavam e as recémchegadas), e os valores das famílias das crianças, as discussões sobre sexualidade são silenciadas. Os discursos morais atrelados a tradições religiosas delegam a função de tratar da sexualidade das crianças ao âmbito privado familiar, concepção que está presente tanto entre 
algumas famílias como no comportamento e nas práticas de algumas professoras. Trabalhar as relações de gênero e sexualidade em uma escola onde as demais professoras também não tiveram uma formação específica gera insegurança por parte da professora que ali chega, mesmo tendo experienciado, em outra escola, uma formação sobre o tema e tendo lá avançado sua prática.

A experiência para tratar sobre a sexualidade não é algo que decorra necessariamente, de uma única formação. Pensando assim, o curso aqui discutido foi composto de três tempos iguais, divididos entre discussões teóricas, experiências na própria escola de modo individual ou em duplas, e apresentação das experiências seguida de debate. No entanto, pode-se reafirmar que o trato com as famílias ainda persiste como ponto problemático para professoras, visto a persistente dificuldade que algumas professoras relataram sobre a aprendizagem desta temática durante o curso. Pelo relato da professora Marina, a dificuldade ainda persiste.

Eu acho que o preconceito é muito grande... E a família acaba não aceitando. Ao mesmo tempo a gente não consegue lidar com isso, não sabe como trabalhar. Porque...[pausa] de que forma eu vou dizer? De que forma eu vou trabalhar, no primeiro contato, o que eu digo para o pai e para a mãe? Não é fácil. Então, é uma barreira. A gente sempre encontra uma barreira. Por isso que eu digo: a gente sabe a teoria, no curso teve a teoria, mas não foi suficiente para a gente sair sabendo lidar com isso. É um assunto muito abrangente. E o resto? Para colocar em prática deveria ter mais momentos. Teria que ter uma segunda parte [sic] (Marina/ACT/EEB Marília Frota).

Ao pensar sobre o relato de Marina, não podemos desconsiderar o fato de que ela está em um trabalho isolado, em uma escola na qual as demais profissionais não tiveram a mesma experiência de formação. Sabemos que um curso, assim como qualquer outra formação, não dispõe de uma fórmula que possa ser seguida nas diversas situações que as professoras encontrarão em suas carreiras docentes, e que, ao longo do tempo, aparecerão muitas variáveis no perfil das famílias e das crianças. Por isso, cabe-nos destacar a importância da autonomia reflexiva sobre o cotidiano escolar, uma vez que a realidade social modifica-se constantemente, exigindo das professoras a reorganização de sua prática docente.

Corroboramos com Pimenta (1996, p. 85), quando esta afirma que "[...] os problemas das práticas docentes não são meramente instrumentais, mas comportam situações problemáticas que requerem decisões num terreno de grande complexidade, incerteza, singularidade e de conflito de valores". É aqui que reafirmamos a importância da formação continuada de professores: só a práxis no decorrer da experiência profissional trará a este docente um conjunto de conhecimentos que subsidiará suas ações, conferindo credibilidade ao seu trabalho. 


\section{A troca de experiências pedagógicas}

Um ponto importante no contexto da pesquisa é o fato da rede municipal de Tubarão ser marcada pela alta rotatividade de professores/as, conforme já sinalizamos nos referindo ao ano em que foi realizada a pesquisa, onde cerca de metade das profissionais eram contratados temporariamente. Segundo as cinco entrevistadas, ainda atuantes na EMEB Esmeralda Lino Silveira, em 2018, a rotatividade das professoras compromete um trabalho mais efetivo, uma vez que a formação continuada sobre gênero e sexualidade foi destinada às professoras que atuaram em 2014, mas as demais que chegaram em 2015, 2016 e 2017 não tiveram a mesma oportunidade de formação.

Em um contexto marcado pela frágil vinculação das docentes com a escola, e de migração frequente de uma escola para a outra em função da Admissão em Caráter Temporário, mesmo uma formação continuada de professoras não consegue produzir resultados coletivos duradouros, ainda que seja útil para minimizar as dificuldades no processo educativo das crianças. ${ }^{\vee}$ Tratando-se de gênero e sexualidade, tais conteúdos em formação continuada são mais necessários, pois raramente estas temáticas estão presentes na formação inicial das professoras $^{\mathrm{vi}}$. Fabiana lamenta:

O que me desconcerta é a questão da rotatividade, porque esses que fizeram, esses que estiveram conosco, teve progresso, a gente viu acontecer, só que a gente perdeu, como tu viu ali. A grande quantidade de pessoas foi para uma escola diferente. Eu acredito que sim, que elas continuam lá plantando as sementinhas em outros lugares, porém, do grupo que fez a gente ficou com poucos, um grupo muito restrito, muito pequeno. Dá para fazer de novo... de onde a gente começa? Do zero, do início (Fabiana/Diretora/EMEB Esmeralda Lino Silveira).

Apesar da rotatividade, algumas professoras avaliam os momentos de planejamento como experiência de formação docente, buscando refletir sobre o cotidiano escolar e problematizando, junto às professoras que chegam, as questões de gênero e sexualidade que permeiam a escola, como ilustramos abaixo:

Na hora do recreio, na aula de planejamento que temos juntas. No início do ano sempre tem também o momento de planejar... E a gente vai trocando ideias, vai mostrando como é que fazemos o trabalho aqui... Porque é uma escola diferenciada... [...] E a gente vai trocando experiências, atividades... "Ah, fulano, essa atividade é legal pra trabalhar tal tema..." sabe? [...] Então na própria conversa que a gente tem com as professoras a gente passa esse nosso jeito de trabalhar... E esse professor também já vai pensando diferente... Agindo diferente (Paula/Professora efetiva/EMEB Esmeralda Lino Silveira). 
Pena que como a gente é ACT e tem toda essa rotatividade a gente não consegue ficar todos sempre no mesmo lugar, mas todos aqueles que chegam no início do ano a gente faz aquela imersão, planejamento, a gente já trabalha a cabeça das outras professoras pra mostrar que a nossa escola é diferente (Camila/ACT/ EMEB Esmeralda Lino Silveira).

As professoras ainda apresentam estratégias diferentes na abordagem crítica da temática com as colegas novas: trocas de experiências sobre planos de aula, as ações durante o recreio e nos momentos de planejamento, assim como, o repasse de textos discutidos durante a formação para as professoras que chegam à escola. Aqui, podemos pensar a ideia do professor-formador, que utiliza a troca de conhecimentos nas falas informais, nos intervalos ou na sala dos professores para vender sua ideia, desenvolvendo uma autonomia intelectual. Percebe-se um vínculo destas professoras com a escola, com o grupo, e que se sentem à vontade para trocar informações sobre a escola, sobre estudantes, sobre suas famílias, uma vez que por dar continuidade ao trabalho de um ano para o outro já conhecem a comunidade escolar. Há, portanto, uma incorporação da ideia de nossa escola, uma escola de trabalho diferenciado, da qual se orgulham. Aliados à pressão conservadora referente a cultura relativa às concepções de gênero e sexualidade na sociedade e na família em especial, a precarização docente com a não oferta de concursos torna-se uma aliada para quebrar redes de experiência que são construídas dentro das escolas e dificultar a práxis dessas professoras.

Além das respostas a situações que fogem aos conteúdos explícitos nos currículos, constatamos haver uma preocupação sobre questões de gênero no planejamento das atividades.

[...] quando tu faz um planejamento de alguma atividade, tu já não faz mais essa divisão. Qualquer atividade. Vai trabalhar o Dia das Mães, o Dia dos Pais... já é diferente, já pensa nos tipos de famílias diferentes, já tem uma preocupação na forma que vai abordar, na hora de escolher uma historinha, na hora de fazer uma apresentação... Já vai pensar na inclusão de todos [...] (Camila/ACT/ EMEB Esmeralda Lino Silveira).

Esta preocupação e inquietação constante da professora resultou em um posicionamento crítico no que diz respeito aos padrões normativos de gênero dentro e fora da escola, sobretudo nos modelos de famílias que fogem da padronização heteronormativa. A atenção no momento da escolha de materiais, a organização do ambiente escolar, as brincadeiras e as atividades proporcionadas aos alunos, e até o material apresentado nos livros infantis são exemplos do posicionamento crítico da professor. Estes revelam uma proposta pedagógica já vivenciada na formação ora estudada, ou seja, comprometida com o rompimento de estereótipos, principalmente quando propunham, realizavam atividades com as crianças e as debatiam no curso. 
Outro ponto levantado por Fernando é o apoio da diretora para a culminância do trabalho destas professoras:

[...] o que eu vejo que faz a diferença também é o apoio do gestor. Aqui a gente tem uma diretora maravilhosa né, que apoia os projetos, que apoia os ideais, que nos apoia naquilo que a gente vem buscando, que tem uma meta, um objetivo. Se a direção fica de fora fica difícil de realizar o trabalho [...] (Fernando/Oficineiro/ EMEB Esmeralda Lino Silveira, grifo nosso).

Aqui, Fernando marca a presença da direção da escola para a efetivação de um trabalho na perspectiva da emancipação. Vista como exemplo por participar dos encontros de formação continuada e pelo forte posicionamento, Fabiana destaca-se como referência na escola para professoras e estudantes. Em um contexto marcado pelo crescente discurso de criminalização dos docentes que abordem as temáticas de gênero e sexualidade, ter uma diretora que possibilite, valorize e busque um trabalho pedagógico não discriminatório é um aspecto que dá suporte às professoras que atuam na unidade escolar. O papel da diretora foi chave não só na sua articulação com a universidade para que o curso ocorresse em sua escola, como para a continuidade do trabalho. Na EMEB Esmeralda Lino Silveira, temos um conjunto de professoras que, apoiadas na figura da diretora, sentem-se confiantes para realizar um trabalho transformador, em uma perspectiva de infância e adolescência na qual crianças possam circular pelos espaços sem as amarras impostas por uma sociedade sexista.

Tendo lutado para levar o curso à sua escola, Fabiana tece uma avaliação positiva sobre a formação continuada:

Hoje dá para fazer muito bem uma leitura de como o curso influenciou, de como influenciou o nosso dia a dia na escola, como é mais fácil se posicionar em determinadas situações... As posturas que se tem. Tem uma diferença sim daquele que fez e daquele que não fez formação. Tem também toda a postura com os alunos, com as crianças. Haviam dois meninos que estavam com as unhas pintadas, e outras crianças vieram denunciar a prática. Nesta hora, eu como diretora fiz o que? Mostrei a minha unha também. Eu disse "oh, a minha é verde!" Claro que eu sei, e os meus colegas também sabem, que aqueles que vieram denunciar aquela prática estavam esperando uma punição, uma penalidade. Mas a forma como a gente hoje percebe as coisas muda todo o desenrolar da situação. Inibe preconceito, desconstrói todo um estereótipo, cria na escola um ambiente de maior liberdade. Nesse momento as crianças, claro, vão se sentir seguras em se expressar. E isso é muito importante (Fabiana/Diretora/EMEB Esmeralda Lino Silveira).

Ao exemplificar com uma situação na qual um menino foi denunciado por estar com as unhas pintadas, Fabiana parece responder às crianças denunciantes de forma totalmente contrária ao que elas esperavam. Podemos pensar, a partir da situação exposta, que se a diretora 
agisse de forma diferente os impactos sobre as crianças que expressavam modos de gênero não binários seriam certamente negativos, na medida em que teria impedido a liberdade de expressão de gênero.

O acompanhamento nos horários intermediários fora da sala de aula, quando realizado por professoras ou outros profissionais despreparados, pode produzir uma negação de identidades, ou mesmo resultar em situações de discriminação. Nesse sentido, o aval da própria diretora tem um peso grande, pois se trata de um sujeito de autoridade na escola. Assim, não sendo alvo de reprovação, as crianças podem se expressar livremente no plano simbólico, explorando possibilidades que vão, pouco a pouco, quebrando estereótipos e constituindo suas identidades múltiplas.

\section{Conclusão}

A escola é um ambiente vivo, espaço no qual os sujeitos reproduzem experiências sociais, como a troca de ideias, valores e interesses diversos. Ali ficam explícitos tensões, conflitos e outras manifestações culturais que fazem parte do processo formativo da identidade das/os estudantes, representando assim a possibilidade de intervenção docente. Assim, a pesquisa em questão procurou destacar, a partir da ótica das professoras, seu papel na formação dos sujeitos. No caso de uma escola de tempo integral, como a EMEB Esmeralda Lino Silveira o olhar atento das professoras é essencial na formação dos sujeitos. Ao discutir a questão de gênero na escola, tomando como referência uma escola de tempo integral, o estudo em questão procurou a partir da ótica das professoras destacar o seu importante papel na formação dos sujeitos, especialmente quando se trata do trabalho com temáticas adversas, como gênero e sexualidade. Diante disso, compreendemos que a escola não pode se omitir em situações de discriminação, mas criar oportunidades a partir de problematizações constantes oriundas do cotidiano, que ferem a liberdade e o respeito às diferenças. Ainda que as dificuldades apareçam, as professoras da EMEB Esmeralda Lino Silveira mostraram que, a partir da formação continuada, há possibilidade de mudança da visão de mundo e de uma nova concepção sobre as temáticas que influenciam diretamente no cotidiano pedagógico da escola. Por compreenderem a importância do trabalho sobre as relações de gênero, as professoras mostraram-se preocupadas com a questão da rotatividade docente, que provoca uma descontinuidade no trabalho. Apesar disto, procuram, na medida do possível, manter as discussões em evidência. Este último ponto parece ser essencial, pois o processo de mudança de atitudes passa pelo trabalho de sensibilização para que os sujeitos possam defender e 
sustentar a temática onde estiverem. Desse modo, reiteramos a necessidade de concursos públicos no magistério, uma vez que a efetivação no quadro de funcionários públicos possibilita a continuidade do trabalho pedagógico, um vínculo maior com a comunidade escolar em que se está inserido e, por consequência, uma prática pedagógica condizente com a realidade vivida pelos alunos

Nota-se, portanto, que a experiência da formação em gênero e sexualidade deu suporte para a identificação de padrões sexistas e para uma reflexão sobre os mesmos, uma vez que criaou espaços para novas proposições ou análises. Em contrapartida, mostrou-se insuficiente para provocar mudanças nas práticas docentes relacionadas à sexualidade, apontada pelas professoras como uma dificuldade que demanda maior formação. Por esta razão, ressaltamos a necessidade da formação permanente de professoras, em direção a um aperfeiçoamento contínuo frente aos novos desafios que surgem na escola, nas mais diversas temáticas.

Por fim, não há dúvidas de que no cotidiano do trabalho de todas as professoras envolvidas nesta formação existe uma visão crítica sobre os desafios da construção de uma sociedade menos desigual,com menos preconceito e discriminação de gênero. Em meio às famílias e religiões com seus apelos morais, e à insegurança gerada pelo medo de não possuir argumentos suficientes para sustentar suas práticas docentes, estas professoras defendem a pluralidade dos sujeitos e, com os recursos que possuem ao seu alcance, tentam materializar aquilo que acreditam ser uma educação de qualidade. Muito embora existam dificuldades no tratamento de algumas questões referentes à temática, uma vez que esta mudança se faz em um processo dialético, no qual as contradições se fazem presentes, as professoras reconhecem a importância da experiência de formação continuada em gênero como potencializadoras da construção de uma sociedade sem desigualdade de classe, raça e sexo.

\section{Referências}

BRASIL. Lei n.13.005, de 25 de junho de 2014. Aprova o Plano Nacional de EducaçãoPNE e dá outras providências. Diário Oficial da União, Brasília, DF., 26 jun. 2014. Disponível em: <https://www.planalto.gov.br/ccivil_03/_ato20112014/2014/lei/113005.htm>. Acesso em: dez. de 2017.

Ministério da Educação. Secretaria da Educação Básica. Base nacional comum curricular. Brasília, DF, 2016. Disponível em: < http://basenacionalcomum.mec.gov.br/\#/site/inicio>. Acesso em: dez. 2017. 
CONNELL, Raelwyn W. Como teorizar o patriarcado. Educação \& Realidade, Porto Alegre, v. 16, n. 2, p. 85-93, 1990.

. Masculinidade Hegemônica: Repensando o Conceito. Estudos Feministas, v. 21, n. 1, 2013. ISSN 0104-026X. Disponível em:

http://www.scielo.br/scielo.php?script=sci_arttext\&pid=S0104-026X2013000100014. Acesso em: fev. 2017.

FORQUIN, Jean-Claude. Escola e cultura: as bases sociais e epistemológicas do conhecimento escolar. Tradução: Guacira Lopes Louro. Porto Alegre: Artes Médicas, 1993.

FRANCO, Maria Amélia do Rosario Santoro. Prática pedagógica e docência: um olhar a partir da epistemologia do conceito. Rev. Bras. Estudos Pedagógicos. Brasília, v. 97, n. 247, set./dez. 2016. ISSN 0034-7183. Disponível em: http://www.scielo.br/scielo.php?pid=S217666812016000300534\&script=sci abstract\&tlng=pt. Acesso em: fev. 2018.

GIROUX, Henry A. Os professores como intelectuais: rumo a uma pedagogia crítica da aprendizagem. Tradução de Daniel Bueno. Porto Alegre: Artes Médicas, 1997.

GRAMSCI, Antonio. Concepção dialética da história. Rio de Janeiro: Civilização Brasileira, 1978.

KONDER, Leandro. O futuro da filosofia da práxis: o pensamento de Marx no século XXI. 2 ed. Rio de Janeiro: Paz e Terra, 1992.

LOURO, Guacira Lopes. Uma leitura da história da educação sob a perspectiva de gênero. Projeto História, São Paulo, v. 11, 1994.

MARTINS, Aline Madalena. A formação continuada de professores/as sobre gênero e sexualidade: contribuições para uma nova prática pedagógica. Dissertação (Mestrado em Educação) - Programa de Pós graduação em Educação, Universidade do Sul de Santa Catarina. Tubarão, 153 p. 2019.

MATTOS, Amana; MAGALDI, Ana Maria Bandeira de Mello; COSTA, Carina Martins; SILVA, Conceição Firmina Seixas; PENNA, Fernando de Araújo; VELLOSO, Luciana; LEONARDI, Paula; ALBERTI, Verena. Educação e liberdade: apontamentos para um bom combate ao Projeto de Lei Escola sem Partido. In: FRIGOTTO, Gaudêncio (Org). Escola "sem" partido: esfinge que ameaça a educação e a sociedade brasileira. Rio de Janeiro: UERJ, LPP, 2017, p. 87-104.

MENDONÇA, Amanda André de; MOURA, Fernanda Pereira de. "Ideologia de gênero" e escola sem partido: a agenda privatizante moralizadora para a educação brasileira. Revista Interinstitucional Artes de Educar. Rio de Janeiro, v. 5, n. 2, ago. 2019. Disponível em: https://www.e-publicacoes.uerj.br/index.php/riae/article/view/44849/30394. Acesso em: 28 mar. 2021.

MIGUEL, Luis Felipe. Da "doutrinação marxista" à "ideologia de gênero" - Escola Sem Partido e as leis da mordaça no parlamento brasileiro. Revista Direito e Práxis. Universidade 
do Estado do Rio de Janeiro. v. 7, n. 15, 2016. Disponível em: Disponível em: http://www.redalyc.org/articulo.oa?id=350947688019. Acesso em: 10 ju. 2021.

MOURA, Fernanda Pereira de. "Escola Sem Partido": relações entre Estado, educação e religião e os impactos no ensino de história. 2016. 89 f. Dissertação - (Mestrado Profissional em Ensino de História) Instituto de História, Universidade Federal do Rio de Janeiro, Rio de Janeiro.

NÓVOA, Antônio. Para uma formação de professores construída dentro da profissão. Revista Educacion. Madrid: 2009. Disponível em: http://www.revistaeducacion.educacion.es/re350/re350_09por.pdf. Acesso em: jun. 2017.

PIMENTA, Selma Garrido. Formação de professores: saberes da docência e identidade do professor. Revista da Faculdade de Educação, USP, v. 1. n. 1, p. 72-89, jul./dez. 1996.

PIMENTA, Selma Garrido; GHEDIN, Evandro. (Org.). Professor Reflexivo no Brasil: gênese e crítica de um conceito. São Paulo: Cortez, 2002.

STROMQUIST, Nelly. Qualidade de ensino e gênero nas políticas educacionais contemporâneas na América Latina. Educação e Pesquisa, São Paulo, v.33, n.1, p. 13-25, jan./abr. 2007. ISSN 1517-9702. Disponível em: http://www.scielo.br/scielo.php?pid=S151797022007000100002\&script=sci_abstract\&tlng=pt. Acesso em: out. 2017.

THOMPSON, Edward Paul. A miséria da teoria ou um planetário de erros: uma crítica ao pensamento de Althusser. Rio de Janeiro: Zahar, 1981.

VÁZQUEZ, Adolfo Sánchez. Filosofia da práxis. Tradução de Luiz Fernando Cardoso. 2. ed. Rio de Janeiro: Paz e Terra, 1997.

WOOD, Ellen Meiksins. Democracia contra o capitalismo: a renovação do materialismo histórico. São Paulo: Boitempo, 2007.

\footnotetext{
i A diretora foi a única integrante que se declarou negra por autoatribuição; a questão racial, todavia, apesar de compor os conteúdos do curso e, também o roteiro de entrevista, não ganhou destaque nas narrativas.

ii Livia, Marina e Camila têm entre 20 a 30 anos; Fabiana, Silvana, Paula e Fernando têm entre 30 e 45 anos; Margarida e Sueli têm entre 60 e 70 anos.

iii A segunda parte da pesquisa de campo foi realizada entre 2018-2019 durante a realização do mestrado de uma das autoras Aline Madalena Martins e compôs parcialmente sua dissertação de Mestrado, sendo citada nas referências bibliográficas como MARTINS, 2019.

iv $\mathrm{O}$ uso das reticências no decorrer das narrativas das professoras indica pausa em suas falas. Para identificar recortes feitos pelas pesquisadoras, utilizamos reticências entre colchetes: [...].

${ }^{v}$ Fernando era o único docente do grupo que já possuía uma trajetória no estudo de relações de gênero e sexualidade. Em 2012, o professor frequentou a disciplina Sexualidade e Orientação Sexual: Cultura e Transformação Social do curso de Pedagogia da UNISUL/SC
} 